\title{
Parameters of lipid and oxidative-antioxidant status in persons aged 18-23 from radiation-contaminated areas under conditions of moderate physical activity
}

\author{
Vadym L. Sokolenko ${ }^{\mathrm{ABCD}}$, Svitlana V. Sokolenko ${ }^{\mathrm{ABD}}$ \\ Bohdan Khmelnytsky National University of Cherkasy, Chercasy, Ukraine \\ Authors' Contribution: A - Study design; B - Data collection; C - Statistical analysis; D - Manuscript Preparation.
}

\section{Abstract}

Purpose: There is a significant amount of data on the stressful effects of exercise, which contain conflicting results. Some publications testify to the adaptive processes and the benefits of optimized exercise for various physiological systems, some deny such an effect. Much controversial is the question of combination the physical exercises of different intensity with other stressors. The purpose of the study: to analyze the parameters of lipid metabolism and oxidative-antioxidant system in persons aged 18-23 who lived in territories with different radioecological status, under conditions of moderate physical activity during exercise.

Material: $\quad$ There were examined 50 students from relatively ecologically clean areas (control group) and 50 students from the IV radiation zone (experimental group). The radiation zone is selected by the dosimetry of soil contamination with ${ }^{137} \mathrm{Cs}$ isotopes after the Chornobyl catastrophe. Age of the examined is 18-23 years. Within the framework of the experimental group there were formed two subgroups: the main group for physical training classes (without signs of morphological-functional disorders) and the group for therapeutic physical training classes (TPTC, persons with signs of vegetative-vascular dystonia syndrome). For the control and experimental main group, classes contained all the planned exercises due to the standard curriculum. The program included a combination of aerobic and strength exercises of moderate intensity. For students with signs of vegetative-vascular dystonia, teachers used specially designed therapeutic exercise complexes. The first analysis of parameters was carried out the day before physical training classes, the second one immediately after the class.

Results: $\quad$ Higher levels of total cholesterol and its lipoprotein fractions (LDL-C and HDL-C), triglycerides, oxidative stress index are detected in the experimental group compared to the control group. At the same time lower levels of sulfhydryl groups (SH) were marked. The absence of statistically significant changes in the analyzed parameters in the control group and the experimental therapeutic group after physical exercises is shown in the study. There were evident tendencies of ceruloplasmin level increase in the control along with the absence of such trends in persons with signs of vegetative-vascular dystonia syndrome. This led to the formation of a significant difference between groups for this antioxidant. There is a significant increase in cortisol level and oxidative stress index in the main group of students from radiation contaminated areas.

Conclusions: Potentiation of various stress factors in persons who experienced the prolonged exposure to Chornobyl accident reduces the adaptive potential of homeostatic systems. This eliminates the optimization of lipid metabolism and oxidative-antioxidant system through moderate exercise. Exercise therapy does not cause a pronounced stress effect.

Keywords: $\quad$ physical training, Chornobyl accident, adaptive reactions, malondialdehyde, oxidative stress index

\begin{abstract}
Glossary
Adaptive reactions are body reactions to the change of environmental conditions. They are especially expressed at extreme influences of environmental factors and controlled by homeostasis systems.

Aerobic exercise is a type of physical activity characterized by the aerobic nature of energy supply (walking, running, swimming, etc.). Usually aerobic exercises are cyclic and performed for a relatively long time. Aerobic exercise is considered an effective type of health-improving physical activity.

Antioxidants are biologically active protein and lowmolecular components. They can prevent or slow down the oxidation processes in the cell by interacting with free radicals and prooxidants.

Chornobyl accident is a radiation catastrophe at the Chornobyl nuclear power plant in 1986 caused a number () Vadym L. Sokolenko, Svitlana V. Sokolenko, 2020 doi:10.15561/20755279.2020.0506
\end{abstract}

of fundamental and applied radiobiological problems in the areas of radionuclide contamination.

High-density lipoprotein cholesterol (HDL-C) is a transport form of cholesterol that carries it back to the liver. It is a high-molecular easily soluble form that does not precipitate. HDL-C plays a protective role against lipid deposition in atherosclerotic plaques

Hypercortisolemia is a condition of elevated cortisol level due to stressful situation.

Low-density lipoprotein cholesterol (LDL-C) is a transport form of cholesterol and desaturated fatty acids from the liver to organs and tissues. LDL-C is poorly soluble and prone to the formation of atherosclerotic plaques in blood vessels, due to the increased ability to lose cholesterol during transportation.

Malondialdehyde (MDA) is a product of lipid peroxidation, a marker of oxidative stress, widely used in the assessment of oxidative status in various biological 
samples.

Oxidative stress (OS) is oxidative processes mobilization, qualitatively different from spontaneous cellular processes. It is characterized by ROS production or inactivation imbalance, as well as oxidants/antioxidants imbalance (in favor of oxidants). Oxidative stress can cause destructive and pathogenic effects in the body.

Oxidative-antioxidant status is the balance between complexes of oxidants and antioxidants in the body.

Physical training is a system of physical exercises increasing the general physical activity of different social groups that is the factor of good health and physical condition maintenance.

Reactive oxygen species (ROS) are free radical components, oxygen ions and peroxides. Their sources are mitochondrial, microsomal, phagocytic electron transport chains of oxidation, etc. They have a high reactivity and a short life span. ROS levels may increase in response to certain endogenous and exogenous factors.

Stress is any change in the homeostasis due to the action of real or potentially dangerous factors characterized by activation of the axis «hypothalamus-pituitary-adrenal». The phase of physiological parameters recovery to homeostatic values is an important component of a normal response to stress. Stress exposure when regulatory systems are unable to restore indicators to optimal values, is called an allostatic load.

Therapeutic physical training classes (TPTC) are a set of strictly dosed physical exercise specially created for treating diseases and injuries, preventing direase recurrence or complications, restoring the health and working ability of patients or disabled people.

Triglycerides are the main lipid component of ultra-low density lipoproteins containing little cholesterol. It is a leading transporter of cholesterol from the liver to the blood.

Vegetative-vascular dystonia is a complex multifactorial syndrome. Its development is caused mostly by genetic factors. It is characterized by impaired neurohumoral and endocrine regulation of tone, mainly at the level of the cardiovascular system.

\section{Introduction}

Proper physical activity is considered an important factor in maintaining optimal health of the human. It affects the intensity of aging, development and progression of chronic diseases associated with age [1,2]. Regular exercise can reduce the destructive manifestations of aging in the elderly at the level of immune status. It can indirectly reduce the impact of negative psychosocial factors and prevent the formation of depressive states $[3,4]$. The mechanisms of the following effect at the molecular level are still being discussed. Perhaps the leading factor is adaptive response in the form of metabolic changes focused on forming a new dynamic balance in the body [5]. The result may be influenced by other factors of individual life: diet, smoking, alcohol and medication. It is believed that an important factor of exercise positive effect is inducing changes in the level of cholesterol, low- density lipoprotein cholesterol (LDL-C) and high-density lipoprotein cholesterol (HDL-C), triglycerides. In other words the effect is manifested in the lipid and lipoprotein metabolism and catabolism. Although a similar result can be obtained through the normal physical work, the value of special training in maintaining a proper lipid profile is more important $[6,7]$. The question of the exercise expedience, duration, intensity, frequency in the implementation of the mechanisms of dynamics of the lipids and lipoproteins level always attracted the attention of scientists $[8,9]$. Here it is recommended to take into consideration the difference between the concepts of "physical activity" and "physical exercise". Also we should mind the lack of clear recommendations for the selection of exercises to improve lipid status [10].

Previous research suggests that physical activity has a positive effect on metabolic status not only by increasing energy expenditure. It also alleviates the psychosocial stress caused by metabolic syndrome and obesity. On the other hand, exercise itself is a stressor. Chronic activation of the hypothalamus-pituitary-adrenal axis, associated with stress, forms a state of hypercortisolemia [11]. Increased stress reactivity may be a prerequisite for the formation of metabolic syndrome [12].

One of the possible factors of physical activity influence on age-related changes in the body is the intensification of oxidative processes. They can cause the destruction of muscle fibers and the suppression of the antioxidant defense $[13,14]$. On the one hand, it is believed that the positive effects of exercise are mostly realized due to the active forms of oxygen. Active forms of oxygen are required for mitochondrial biogenesis and effective muscle contraction [15]. On the other hand, an increase in the concentration of reactive oxygen species is a sign of the oxidative processes mobilization. They, in turn, are realized by lipid peroxidation, in other words, it is the manifestation of oxidative stress [16].

Oxidative stress (OS), in particular during intense physical activity, is characterized by an imbalance between the production/inactivation of reactive oxygen. There is an imbalance between oxidants and antioxidants (in favor of oxidants). This can cause destructive and pathogenic effects in the body $[5,17]$. Oxidative stress manifestations vary depending on the type of exercise. High-intensity exercise increases oxidative stress, and medium-intensity exercise is usually associated with decreased OS level [18]. Accordingly, the exercise intensity can be considered the factor of health benefits [19].

However, there were described the cases when longterm exposure to medium-intensity aerobic exercise has led to increased levels of malondialdehyde (MDA, a marker of oxidative stress) in laboratory animals [20]. Periodic increase in training load with weight reduced lipid peroxidation and, accordingly, had a positive effect on the development of oxidative stress [21].

In previous years, a significant amount of data has been accumulated on the stressful effects of physical activity with rather contradictory results. Some studies propose the hypothesis of adaptation to cross-stress. It 
finds the benefits of optimized exercise for the formation of adaptive processes to strong social stressors. Other researches deny this effect. Many publications indicate that the positive or negative effect of training exercise on the human body depends on the various factors. It includes the type, intensity, frequency and duration of exercise, the rate of body parameters returning to its original level. The conclusions could be influenced by the methodological difference of conducting experiments that indicates the need to continue the scientific research in this direction $[4,11,22]$.

It should be taken into account that a strongly pronounced increase in the level of reactive oxygen species (ROS) with subsequent cell damage is observed in conditions of environmental pollution of varying nature [17]. In our previous studies, we have found an increase in oxidative stress in people who have lived for a long time in radiation-contaminated areas. Also the signs of lipid status disorders were discovered [23-25]. However, in the same cohort, dosed physical exercise during physical training classes led to short-term changes in the immune system within the homeostatic norm. It indicated a low level of physical stress and effective recovery [26].

Purpose of study: to analyze the parameters of lipid metabolism and oxidative-antioxidant system in persons aged 18-23 who lived in areas with various radioecological status, under conditions of moderate physical activity during exercise.

\section{Materials and methods}

\section{Participants.}

The control group includes 50 students of Bohdan Khmelnytsky National University of Cherkasy (Ukraine) from radiation-free areas, without signs of acute or chronic diseases. The experimental group includes 50 students from the territory of enhanced radioecological control (zone IV, the status was granted by dosimetric assessment after the Chornobyl accident in 1986). Within the experimental group there are two subgroups formed: 25 healthy people (the main group) and 25 people with signs of vegetative-vascular dystonia (the therapeutic group). Age of students is 18-23 years. The conclusion about the state of health of the examined students was made by the doctors of the sanatorium "Edem" of Cherkasy National University. The study was conducted in compliance with the ethical principles of the European Convention and the Helsinki Declaration (ethics principles regarding human experimentation). It was confirmed by the Bioethics Commission of the University. Examined provided written approvals for analysis and subsequent disclosure.

\section{Procedure.}

Biomaterial collection techniques, used in the study reagents and methods for assessing the level of cortisol, lipid and oxidative-antioxidant status are described in detail in previous publications [23-25]. To assess the intensity of oxidative processes used the method developed by Korol and Myhal [27].

The research was conducted in late September, early October, after the adaptation period due to the beginning of studies. First-year students were not involved in the research. Physical activity in physical training classes was supervised by the teachers. Class duration is 80 minutes. For the control and experimental main groups, classes contained all the planned exercises due to the standard curriculum. The aerobic and strength exercises of moderate intensity were combined [28]. For people with signs of vegetative-vascular dystonia, teachers used specially designed therapeutic exercise complexes. They include breathing exercises, stretching exercises and coordination exercises, time-limited action games [29].

The first analysis of parameters was carried out the day before physical training classes, the second one immediately after the class.

Statistical Analysis.

The calculated statistical parameters are presented in the table in the form of average values and standard error $(M \pm m)$. Student's t-test was used to compare data between groups and parameters before and after exercising. In the case where the data did not show a normal distribution, the Mann-Whitney U test was used. Statistical significance of the parameter's difference is reflected in three levels $(\mathrm{P}<0.05 ; \mathrm{P}<0.01 ; \mathrm{P}<0.001)$.

\section{Results}

It was found that in the control group the concentration of cortisol was within homeostatic norm. Physical training caused a tendency to increase in the concentration of cortisol, but the changes were not statistically significant. Examined from areas of radiation contamination (both main and therapeutic group) showed the initial concentration of cortisol significantly higher than the control values $(\mathrm{P}<0.001)$. The index was at the upper values of the homeostatic norm. Physical training caused a tendency to increase in the therapeutic group and a significant increase in the main group $(\mathrm{P}<0.05)$. The rate after exercise is significantly higher than the control under the same conditions $(\mathrm{P}<0.001)$ in both groups of students from radiation-contaminated areas (Table 1 ).

Prior to physical training, total cholesterol concentration was shifted to the upper values of the homeostatic norm in the main group from radiationcontaminated areas. The index exceeded the upper values of the norm in the therapeutic group (with signs of vegetative-vascular dystonia) The index in both groups from radiation-contaminated areas is significantly higher than the control $(\mathrm{P}<0.001)$. After physical activity any significant changes were not detected in either the control or experimental groups (Table 1).

Similar features were observed for triglyceride concentration and high-density lipoprotein cholesterol. In both experimental groups from radiation-contaminated areas, the rates were significantly higher than the control both before and after exercise $(\mathrm{P}<0.001)$. Under conditions of physical activity any significant changes are absent in all the groups of examined students. Although some tendencies to increase (in average) in the level of HDL-C and decrease in the level of triglycerides were observed in all the groups (Table 1). 
Table 1. Physical activity influence caused by physical training lessons on cortisol parameters, lipid profile and oxidativeantioxidant status of the examined $(\mathrm{M} \pm \mathrm{m})$

\begin{tabular}{|c|c|c|c|c|c|c|}
\hline \multirow[b]{2}{*}{ Components } & \multicolumn{2}{|l|}{ Control, $n=50$} & \multicolumn{2}{|c|}{ The main group, $n=25$} & \multicolumn{2}{|c|}{ The therapeutic group, $\mathbf{n}=\mathbf{2 5}$} \\
\hline & $\begin{array}{l}\text { before } \\
\text { exercise }\end{array}$ & after exercise & $\begin{array}{l}\text { before } \\
\text { exercise }\end{array}$ & after exercise & $\begin{array}{l}\text { before } \\
\text { exercise }\end{array}$ & after exercise \\
\hline $\begin{array}{l}\text { Cortisol, } \\
\mathrm{nmol} / \mathrm{l}\end{array}$ & $349.1 \pm 10.12$ & $387 \pm 18.44$ & $\begin{array}{l}627.2 \pm 21.10 \\
* * *\end{array}$ & $\begin{array}{l}693.1 \pm 15.9 \\
* * * \#\end{array}$ & $\begin{array}{l}620.2 \pm 24.31 \\
* * *\end{array}$ & $\begin{array}{l}641.1 \pm 19.02 \\
* * * \$\end{array}$ \\
\hline $\begin{array}{l}\text { Total cholesterol, } \\
\mathrm{mmol} / \mathrm{I}\end{array}$ & $3.06 \pm 0.28$ & $2.81 \pm 0.16$ & $\begin{array}{l}5.35 \pm 0.51 \\
* * *\end{array}$ & $\begin{array}{l}5.32 \pm 0.85 \\
* *\end{array}$ & $\begin{array}{l}6.68 \pm 0.84 \\
* * *\end{array}$ & $\begin{array}{l}6.65 \pm 0.61 \\
* * *\end{array}$ \\
\hline $\begin{array}{l}\text { Triglycerides, } \\
\mathrm{mmol} / \mathrm{l}\end{array}$ & $0.52 \pm 0.08$ & $0.50 \pm 0.07$ & $\begin{array}{l}0.93 \pm 0.08 \\
* * *\end{array}$ & $\begin{array}{l}0.90 \pm 0.06 \\
* * *\end{array}$ & $\begin{array}{l}0.97 \pm 0.04 \\
* * *\end{array}$ & $\begin{array}{l}0.96 \pm 0.06 \\
* * *\end{array}$ \\
\hline $\begin{array}{l}\text { High density } \\
\text { lipoprotein } \\
\text { cholesterol, } \\
\mathrm{mmol} / \mathrm{l}\end{array}$ & $1.07 \pm 0.07$ & $1.16 \pm 0.07$ & $\begin{array}{l}1.64 \pm 0.09 \\
* * *\end{array}$ & $\begin{array}{l}1.69 \pm 0.08 \\
* * *\end{array}$ & $\begin{array}{l}1.47 \pm 0.07 \\
* * *\end{array}$ & $\begin{array}{l}1.56 \pm 0.07 \\
* * *\end{array}$ \\
\hline $\begin{array}{l}\text { Low density } \\
\text { lipoprotein } \\
\text { cholesterol, } \\
\mathrm{mmol} / \mathrm{l}\end{array}$ & $1.82 \pm 0.11$ & $2.05 \pm 0.13$ & $\begin{array}{l}3.15 \pm 0.41 \\
* *\end{array}$ & $\begin{array}{l}2.92 \pm 0.40 \\
*\end{array}$ & $\begin{array}{l}4.92 \pm 0.58 \\
* * * \$\end{array}$ & $\begin{array}{l}4.25 \pm 0.39 \\
* * * \$\end{array}$ \\
\hline $\begin{array}{l}\text { Malondialdehyde, } \\
\mathrm{mmol} / \mathrm{l}\end{array}$ & $125.4 \pm 27.51$ & $132.1 \pm 23.14$ & $130.3 \pm 10.01$ & $142.2 \pm 10.99$ & $141.2 \pm 9.99$ & $143.1 \pm 8.11$ \\
\hline $\begin{array}{l}\text { Ceruloplasmin, } \\
\mathrm{g} / \mathrm{l}\end{array}$ & $0.24 \pm 0.02$ & $0.28 \pm 0.02$ & $0.22 \pm 0.01$ & $0.26 \pm 0.02$ & $0.21 \pm 0.02$ & $\begin{array}{l}0.21 \pm 0.02 \\
* *\end{array}$ \\
\hline $\begin{array}{l}\text { Transferrin, cond. } \\
\text { un. }\end{array}$ & $5.33 \pm 1.01$ & $5.36 \pm 1.08$ & $4.52 \pm 0.63$ & $4.63 \pm 0.87$ & $4.25 \pm 0.85$ & $4.32 \pm 0.96$ \\
\hline $\begin{array}{l}\text { SH-groups, } \\
\mathrm{mmol} / \mathrm{I}\end{array}$ & $2.52 \pm 0.03$ & $2.62 \pm 0.05$ & $\begin{array}{l}1.84 \pm 0.04 \\
* * *\end{array}$ & $\begin{array}{l}1.99 \pm 0.06 \\
* * *\end{array}$ & $\begin{array}{l}1.63 \pm 0.06 \\
* * * \$ \$\end{array}$ & $\begin{array}{l}1.67 \pm 0.04 \\
* * * \$ \$ \$\end{array}$ \\
\hline $\begin{array}{l}\text { Oxidative stress } \\
\text { index, un. }\end{array}$ & $1.03 \pm 0.04$ & $1.05 \pm 0.06$ & $\begin{array}{l}1.37 \pm 0.04 \\
* * *\end{array}$ & $\begin{array}{l}1.52 \pm 0.05 \\
* * * \#\end{array}$ & $\begin{array}{l}1.43 \pm 0.05 \\
* * *\end{array}$ & $\begin{array}{l}1.44 \pm 0.05 \\
* * *\end{array}$ \\
\hline
\end{tabular}

Notes: ${ }^{*}-\mathrm{P}<0.05 ;{ }^{*}-\mathrm{P}<0.01 ;{ }^{* * *}-\mathrm{P}<0.001$ compared to the control under the same conditions; \# $-\mathrm{P}<0.05$ compared to the index before exercise; $\$-P<0.05 ; \$ \$-P<0.01 ; \$ \$-P<0.001$ compared to the index in the main group under the same conditions

Before physical activity a significantly higher rate of low-density lipoprotein cholesterol was found compared to the control. The effect is marked in both main $(\mathrm{P}<0.01)$ and therapeutic $(\mathrm{P}<0.001)$ groups of students from radiation-contaminated areas In the therapeutic group the rate is significantly higher than in the main group $(\mathrm{P}<0.05)$. There are no statistically significant changes under conditions of physical exercise in all the groups. However, students from radiation-contaminated areas, especially in the therapeutic group, have a tendency to the rate decrease. After exercise, the rate in the main group is significantly higher than in the control under the same conditions $(\mathrm{P}<0.05)$. In the therapeutic group it is significantly higher than in the control $(\mathrm{P}<0.001)$ and in the main group $(\mathrm{P}<0.05)$ (Table 1$)$.

There are no significant differences between the analyzed groups before physical exercise in the concentration of malondialdehyde, ceruloplasmin and transferrin. There are no significant changes in exercise conditions as well (Table 1). There are pronounced trends to increase in ceruloplasmin concentration on the average value in the control group. The same trends are absent in the group of people with the signs of vegetativevascular dystonia. This led to the fact that the rate became significantly lower in the therapeutic group than in the control group after exercise $(\mathrm{P}<0.01)$ (Table 1).

Before exercise, SH-groups concentration in the examined from the main group was significantly lower than in the control $(\mathrm{P}<0.001)$. In the therapeutic group it is lower than both in the control $(\mathrm{P}<0.001)$ and in the main group $(\mathrm{P}<0.01)$. No significant changes were found for all the groups. After exercise, there was a significant difference in the rate compared to the control. The effect was marked both in the main group of students from contaminated areas $(\mathrm{P}<0.001)$ and in the therapeutic group $(\mathrm{P}<0.001)$. In the therapeutic group index remained significantly lower than in the main group $(\mathrm{P}<0.001)$ (Table 1).

The oxidative stress index was significantly higher in both experimental groups than the control, both before and after exercise $(\mathrm{P}<0.001)$. Under conditions of physical activity, the rate significantly increased only in the main 
group of students from radiation-contaminated areas ( $\mathrm{P}$ $<0.05)$ (Table 1).

\section{Discussion}

Cortisol level remains the leading biomarker of the hypothalamus-pituitary-adrenal activity and the reactions of the physiological response of the body to acute or prolonged stress [30]. Increased cortisol level in the examined from radiation-contaminated areas before exercise indicated the chronic stress. Ionizing radiation is a stressor for the human body. Moreover, it acts both as a physical and psychological factor, in particular, with a long-term awareness of the constant potential health risk [31-33]. Under conditions of physical activity during physical training lessons, cortisol level significantly increased only in the main group of students from the IV radiation zone (Table 1). However, cortisol rate did not reach such high values as in the period of intensified psycho-emotional load caused by the examination session. This effect, when cortisol level also increased in the control group, was observed in our previous studies $[24,25]$. Thus, we can distinguish the lack of the evident stress effect of physical activity. Cortisol level increase in the main group of students could be a sign of potentiation of previous chronic radiation exposure and exercise. The important factor is no increase in cortisol levels in the therapeutic group. The positive aspects of this effect can be assessed in comparison with the analysis of other analyzed parameters.

Hypercortisolemia is associated with metabolic syndrome, accumulation of total cholesterol and lowdensity lipoprotein cholesterol, as well as decrease in the level of high-density lipoprotein cholesterol [34, 35]. Lipoprotein lipase (LPL) activity increases that, in turn, leads to an increase in triglycerides. Such processes are mobilized in individuals with dysregulated or hyperactive stress response [11,36, 37]. Correction of elevated cortisol level usually improves the state of hyperlipidemia [38]. Our previous studies have shown associative relations between cortisol level and lipid profile in individuals from the areas of enhanced radioecological control. Strongly pronounced lipid parameters imbalance was observed in persons with signs of vegetative-vascular dystonia and dysfunctions of thyroid status [23].

Taking into consideration the initial elevated level of cortisol in the experimental groups, its further increase during physical exercise could be characterized as an unfavorable factor. However, it is necessary to take into account the possible positive effect of exercise on the lipid profile. There are studies conducted for Australian farmers who have experienced severe emotional stress and were inclined to metabolic disorders. It was shown that a set of physical exercises caused a significant reduction in obesity. However, it had little effect on cortisol concentrations, anxiety, depression and stress [39].

There are data indicating on elevated levels of total cholesterol and LDL-C in individuals of different sexes who had a high level of physical activity during the life
[40]. However, a significant number of publications indicate a positive effect of exercise on the lipoprotein profile of examined. It applies to people of different ages, starting from childhood and ending with the old age [41, 42]. Usually, the ratio of low and high density lipoproteins cholesterol, as well as the level of triglycerides, is analyzed when assessing the lipid profile. Elevated LDL-C indicates an excess of lipids in the blood. Along with triglyceride excess, it causes a risk of cardiovascular dysfunction. In particular, it is a marker of atherosclerotic diseases [10, 43, 44]. In contrast, HDL-C, transporting lipids to the liver for further utilization is considered to be protective for cardiovascular system. However, a significant increase in this parameter can also create the preconditions for the pathologies development [45, 46]. Hypertriglyceridemia has received less attention in clinical practice, although it is clearly associated with diabetic conditions and pancreatitis $[47,48]$.

Thus, in our case, a group of people with signs of vegetative-vascular dystonia can be considered a risk group. This is the risk of metabolic syndrome formation and the development of cardiovascular disorders complications. They are caused by $\mathrm{s}$ a significantly elevated LDL-C level. Under conditions of physical activity, no statistically significant changes in the lipid profile parameters of the examined were detected. However, there are signs of positive effect of physical exercises, especially pronounced in people from the therapeutic group. Here belong the tendency to decrease in the level of LDL-C against the background of LDL-C increase and triglycerides decrease. (Table 1).

Lipid profile changes during exercise can be influenced by several factors. First of all, it's exercise intensity.

Analysis of publications shows that low and medium intensity aerobic exercises lead to a significant reduction in the level of LDL-C. It is believed such exercises determine the effective use of lipids as a source of energy, supporting the activity of the cardiovascular system [49, 50]. Moderate-intensity exercises keep the level of LDL-C and triglycerides lower than high-intensity exercises. Under the same conditions HDL-C level is contrarily higher. At the same time no difference in the level of total cholesterol between the groups of physical activity of different intensity may be observed. Such tendencies are representative not only for aerobic, but also for strength training $[10,51]$.

The second effectiveness factor is exercise type. Aerobic exercises (running, cycling) are considered more favorable for lipid profile improving. However, the result is mostly determined by the intensity $[10,52]$. The combination of aerobic and strength exercises usually gives a result similar to individual aerobic. Moreover, the statistical significance of lipid profile changes is noted for the elderly people. In young ones there were only trends in the same direction [53].

The next effectiveness factor is the age of the examined, although the results are contradictory in this regard. There are reports of the absence of a clear correlation between physical activity and lipoprotein profile in the elderly 
[42]. At the same time, a study of college students with the signs of obesity or overweight showed certain trends. An increase in HDL-C and decrease in triglyceride level during regular fitness is observed. It is especially evident in females [54]. Fitness also improved the lipid profile of obese adult women [55].

Another important factor is previous physical form. Usually the concentrations of total cholesterol and LDL-C are significantly higher in groups that did not have regular exercise. The concentration of high-density lipoprotein cholesterol is higher in the group of trained individuals [56]. It was reported that untrained young males showed the ratio of low/high density lipoproteins higher than in the trained group. The effect appeared both before and after exercise However, cortisol level (also elevated) in this group was optimized after exercise [57]. In general, people previously having low physical activity, showed a correlatation of its growth with an improvement in triglycerides and HDL-C. Moreover, taking into account the data variability, the main effect of exercise is suggested to be an increase in HDL-C [10].

The duration of the physical training course should not be neglected either. In particular, a significant decrease in the level of low-density lipoprotein cholesterol was observed after 2-6 months of training [42, 55, 58]. There are data on a certain racial and gender variability of the lipid profile response to exercise [59].

Metabolic changes being formed in the body of athletes during intense physical and emotional load are characterized by specific features. On the one hand, physical activity helps to increase overall physical efficiency, energy supply, optimization of maximum oxygen consumption [60]. On the other hand it leads to the body deconditioning and the oxidative stress formation. There is evidence that at the beginning of the training period the level of malondialdehyde in the group of athletes is higher than in the control group [56]. The rate increased even more by the end of the training period that indicates the body deconditioning and the oxidative stress formation. In the middle of the training period, the rate declining tendency was observed, that was characterized as the oxidative processes hierarchy change [61, 62]. Intensification of lipid peroxidation was observed in middle-aged and elderly men during long training with combined strength and exercise tolerance circuit. This gave the reason to talk about the importance of the time factor in the response of oxidative and antioxidant systems to physical stress [63]. However, even short-term intense exercise (running, swimming) can cause the MDA level increase and the effect lasts at least 24 hours [64, 65]. In particular, the MDA concentration increase after intense exercise was found in young people of different sexes in the postpubertal period. This indicates the mobilization of oxidative stress [66]. Intensification of oxidative processes in trained individuals during exercise was less pronounced than in untrained group [67]. There are data demonstrating the absence of pronounced changes in the level of malondialdehyde during 12-week training [68].

Malondialdehyde (MDA), as a product of lipid peroxidation, is its reliable marker. It is widely used in the assessment of oxidative status in various biological samples $[16,69,70]$. The MDA level assessment under conditions of exogenous influences should be performed in combination with the antioxidant status assessment. However, even in this case, contradictory results are often obtained. Some studies have described the absence of a significant increase in the level of MDA, in others its presence is marked $[71,72]$. Obviously, in addition to the time factor, the training intensity is essential for the effect manifestation. This is confirmed by the positive correlations between exercise intensity, antioxidant and malondialdehyde concentration [56].

There is comparison of the groups of students who had standard training and balanced physical therapy classes. It showed no difference in the level of MDA both at the beginning of the 8 -week training period and at the end. Moreover, at the beginning of the training period there was a tendency to the MDA level increase after classes. At the end of training period a fairly stable level was marked. There was a tendency to gradually reduce the level of MDA during the training period [73].

There is an analysis of 8-week classes of various types in a group of men aged 60-80 years. Aerobic, strength or combined classes three times a week for 1 hour. We marked a decrease in the level of MDA, regardless of the type of exercise. The effect was characterized as the oxidative stress reduction. Antioxidant protection parameters also improved, however, the value depended on the type of exercise performed. This indicated the variability of the antioxidant protection mechanisms depending on the type of exercise [4]. In patients with insulin-independent diabetes, 12-week aerobic exercise caused a tendency to the MDA level decrease. There was physical and mental condition improvement [74].

Ceruloplasmin, transferrin and sulfhydryl groups are recognized antioxidants [75-77]. Particular attention is paid to ceruloplasmin. It is a regulator of copper and iron ions homeostasis in the body and free radicals formation protector [78]. Antioxidant status is usually higher in trained individuals before exercise and it was improved in untrained individuals after exercise [57]. In our studies, there is no significant difference between the analyzed groups in the initial concentration of malondialdehyde. It relates to the most parameters of antioxidant status. Only SH-groups concentration in the main group of students from radiation-contaminated areas is significantly lower than in the control. In the therapeutic group it is significantly lower than in the other two groups (Table 1). After physical training, there were no significant changes in the parameters. However, different tendencies led to a significant increase in the index of oxidative stress in the examined of the main experimental group (Table 1). Thus, they showed a tendency of increase in the levels of ceruloplasmin and sulfhydryl groups that did not compensate the tendencies of increase in the levels of malondialdehyde. In general, the oxidative stress index is significantly higher in all experimental groups than the control both before and after exercise. It is clear that in 
conditions of environmental pollution of various nature, the level of ROS increases [17]. Obviously, the effect is caused by long-term living in the territories of the IV radiation zone. It happened in the periods of ontogenesis that is important for the formation of physiological homeostatic systems. As a result, it created the tension of the antioxidant system with the following specific response to exogenous influence. On the other hand, there is the lack of the oxidative stress index increase in the therapeutic group. It indicates the optimal selection of exercises for therapeutic training course.

Vegetative-vascular dystonia syndrome is a complex of dysfunctions at the level of autonomic regulation and vascular insufficiency. This requires careful physiotherapeutic rehabilitation, in particular, through exercise [79]. Regular exercise is considered an important physiological stimulus for adaptive responses. They improve the regulation of vascular tone and, consequently, vascular endothelial function [80]. In addition, there are data on the associated nature of neurodegenerative diseases with increased oxidative stress. Under such conditions regular exercise can increase the activity of antioxidant system and the system of oxidative damage repair $[81,82]$.

When assessing any stress response as the cause of allostatic load, it is recommended to take into consideration various parameters. They are the value (intensity) of stress, its frequency, duration, rate of parameters' return to the initial level, etc. [11]. ROS are the important signal molecules for adaptive response. Detoxification and normalization of ROS parameters due to exercise depends on various factors. These are age, sex, level of physical activity, environmental conditions, genetic characteristics of the individual, lifestyle, nutrition quality. Increased as a result of metabolic processes, ROS production leads to oxidative damage. However, it also stimulates the antioxidant protection that eliminates much of the damage [83].

Thus, we considered the age of the examined, the lack of trained individuals, low and medium intensity of the exercise. Accordingly, we expected more pronounced changes in lipid status and improved parameters of antioxidant status. Perhaps a significant factor was the study period. The analysis was performed almost at the beginning of the semester. Any significant changes could be expected at the end of the school year.

It is believed the benefit of regular short-term exercise is connected with the stimulation of oxidative processes.
ROS level increase continues to the values causing significant but acceptable damage. This, in turn, stimulates adaptive responses. According to the theory of hormesis, they protect against stress effects of greater intensity or strength. The following effect, being realized at the molecular level, can serve as a protective factor against diseases associated with ROS. In particular, age-related changes $[18,84]$. However, the examined from radiationcontaminated areas have some specifics. The adaptive reactions realization could be affected by failures in the regulation of lipid and oxidative-antioxidant profile. The failure probability is described in our previous publications [23-25]. When selecting exercise for this cohort, it is important to consider the risk of all stressors' potentiation. A special attention should be paid to the social anxiety as a factor of significant hypercortisolemia [85].

\section{Conclusions}

Students from the control group did show statistically significant changes of the analyzed parameters during physical activity. The group of exercise therapy was formed by the people from radiation-contaminated areas with signs of vegetative-vascular dystonia syndrome. There are no significant changes in lipid metabolism and oxidative-antioxidant status in the group. This indicates the absence of a pronounced stress effect of specially selected exercises. People from the radiationcontaminated areas performed the standard set of aerobic and strength exercises. There is a significant increase in cortisol level and oxidative stress index in the group. This effect may indicate the potentiation of various stressors. The group from the IV radiation zone has the lack of positive dynamics of the analyzed parameters after physical education. This may be a sign of a short period of training and failure of adaptive homeostatic systems.

\section{Acknowledgements}

The authors express their sincere gratitude to the chief physician of the "Edem" sanatorium at the Bohdan Khmelnytsky National University of Cherkasy Pinkovska L. O. for the examination of the experimental group and control group of students and assessment of their health status, and to the medical staff of the sanatorium for blood sampling.

\section{Conflict of interest}

The authors state that there is no conflict of interest. 


\section{References}

1. Ciolac EG. Exercise training as a preventive tool for agerelated disorders: a brief review. Clinics. 2013; 68(5): 710-17. https://doi.org/10.6061/clinics/2013(05)20

2. Zampieri S, Pietrangelo L, Loefler S, Fruhmann H, Vogelauer M, Burggraf $\mathrm{S}$, et al. Lifelong physical exercise delays age-associated skeletal muscle decline. J Gerontol: Series A. 2015; 70(2): 163-73. https://doi.org/10.1093/gerona/glu006

3. Larbi A, Franceschi C, Mazzatti D, Solana R, Wikby A, Pawelec G. Aging of the immune system as a prognostic factor for human longevity. Physiology. 2008; 23(2): 64-74. https://doi.org/10.1152/physiol.00040.2007

4. Sbardelotto ML, Pedroso GS, Pereira FT, Soratto HR., Brescianini SMS, Effting PS, et al. The effects of physical training are varied and occur in an exercise type-dependent manner in elderly men. Aging Dis. 2017; 8(6): 887. https://doi.org/10.14336/AD.2017.0209

5. Magherini F, Fiaschi T, Marzocchini R, Mannelli M, Gamberi T, Modesti P, et al. Oxidative stress in exercise training: the involvement of inflammation and peripheral signals. Free Radic Res. 2019; 53(11-12): 1155-65. https://doi.org/10.1080/10715762.2019.1697438

6. Berg A, Halle M, Franz I, Keul J. Physical activity and lipoprotein metabolism: epidemiological evidence and clinical trials. Eur J Med Res. 1997; 2(6): 259-64.

7. Forrest KYZ, Bunker CH., Kriska AM, Ukoli FA, Huston SL, Markovic N. Physical activity and cardiovascular risk factors in a developing population. Med Sci Sports Exerc. 2001; 33(9): 1598-604. https://doi.org/10.1097/00005768-200109000-00025

8. Goldberg L, Elliot DL. The effect of physical activity on lipid and lipoprotein levels. Med Clin N Am. 1985; 69(1): 41-55.

9. Sokolenko VL, Sokolenko SV (2009). The influence of physical loadings at the cellular immunity and cholesterol level. Pedagogics, Psychology, Medical-Biological Problems of Physical Training and Sports. 2009; 10: 219-221 (in Ukrainian).

10.Mann S, Beedie C, Jimenez A. Differential effects of aerobic exercise, resistance training and combined exercise modalities on cholesterol and the lipid profile: review, synthesis and recommendations. Sports Med. 2014; 44(2): 211-21. https://doi.org/10.1007/s40279-013-0110-5

11.Holmes ME, Ekkekakis P, Eisenmann JC. The physical activity, stress and metabolic syndrome triangle: a guide to unfamiliar territory for the obesity researcher. Obes Rev. 2010; 11(7): 492-507. https://doi.org/10.1111/j.1467-789X.2009.00680.x

12.Björntorp P. Do stress reactions cause abdominal obesity and comorbidities?. Obes Rev. 2001; 2(2): 73-86. https://doi.org/10.1046/j.1467-789x.2001.00027.x

13. Woods JA, Wilund KR, Martin SA, Kistler BM. Exercise, inflammation and aging. Aging Dis. 2012; 3(1): 130-40.

14.Bouzid MA, Hammouda O, Matran R, Robin S, Fabre C. Changes in oxidative stress markers and biological markers of muscle injury with aging at rest and in response to an exhaustive exercise. PloS ONE. 2014; 9(3): e90420. https://doi.org/10.1371/journal.pone.0090420

15.Henríquez-Olguín C, Renani LB, Arab-Ceschia L, Raun $\mathrm{SH}$, Bhatia A, Li Z, et al. Adaptations to highintensity interval training in skeletal muscle require NADPH oxidase 2. Redox Biol. 2019; 24: 101188. https://doi.org/10.1016/j.redox.2019.101188

16.Ito F, Sono Y, Ito T. Measurement and clinical significance of lipid peroxidation as a biomarker of oxidative stress: oxidative stress in diabetes, atherosclerosis, and chronic inflammation. Antioxidants. 2019; 8(3): 72. https://doi.org/10.3390/antiox8030072

17.Mihalaş E, Şerban LI, Matei D, Caşcaval D, Galaction AI Changes of oxidative stress caused by physical activity. Studia Universitatis Babes-Bolyai Chemia. 2019; 64(2): 35-47. https://doi.org/10.24193/subbchem.2019.2.03

18.Bouzid MA, Filaire E, McCall A, Fabre C. Radical oxygen species, exercise and aging: an update. Sports Med. 2015; 45(9): 1245-61. https://doi.org/10.1007/s40279-015-0348-1

19. Gebel K, Ding D, Chey T, Stamatakis E, Brown WJ, Bauman AE Effect of moderate to vigorous physical activity on all-cause mortality in middle-aged and older Australians. JAMA Intern Med. 2015; 175(6): 970-7. https://doi.org/10.1001/jamainternmed.2015.0541

20.Ilyas EII, Utami TP, Siagian M, Santoso DIS, Prijanti AR Effects of Moderate-Intensity Exercise Training on Stress Oxidative Marker: Malondialdehyde and Superoxide Dismutase Activity in Abdominal Aorta of Juvenile Rats. IJRG. 2017; 5(12): 99-105. https://doi.org/10.5281/zenodo.1133607

21.Zabet A, Ghazalian F, Nik-Bakht H. The Effect of Resistance Training with Moderate and Progressive Intensity on Indices of Oxidative Stress (Serum 8-Isoprostane, Malondialdehyde and Reduced Glutathione Levels) in Young Healthy Men. J of Clin Res Paramed Sci. 2018; 7(1). https://doi.org/10.5812/jcrps.80469

22.Sothmann MS. The Cross-Stressor Adaptation Hypothesis and Exercise Training. In: Acevedo EO, Ekkekakis P, editors, Psychobiology of Physical Activity. Human Kinetics; 2006. P. 149-60.

23. Sokolenko VL, Sokolenko SV. The interaction between lipid exchange and thyroid status in the conditions of prolonged influence of small doses of radiation. Regul Mech Biosyst. 2017; 8(2): 231-8 (in Ukrainian). https://doi.org/10.15421/021736

24. Sokolenko VL, Sokolenko SV, Sheiko VI, Kovalenko OV. Interconnection of the immune system and the intensity of the oxidative processes under conditions of prolonged exposure to small doses of radiation. Regul Mech Biosyst. 2018; 9(2): 167-76. https://doi.org/10.15421/021825

25. Sokolenko VL, Sokolenko SV. Interdependence of oxidative/antioxidant system indicators and thyroid status under conditions of prolonged exposure to small doses of radiation. Regul Mech Biosyst. 2019; 10(2): 219-27. https://doi.org/10.15421/021933

26.Sokolenko VL, Sokolenko SV. Vplyv pomirnykh fizychnykh navantazhen na pokaznyky imunnoi systemy $\mathrm{u}$ meshkantsiv radiatsiino zabrudnenykh terytorii [Influence of moderate physical load on parameters of the immune system among residents of contaminated areas]. Regul Mech Biosyst. 2016; 7(1): 48-52 (in Ukrainian). https://doi.org/10.15421/021609

27.Korol LV, Myhal LA. Method of integral evaluate of oxidantantioxidant balance in blood serum. Patent № 102192 UA, CIP G01N 33/48 (2006.01). № a 201205647. 08.05.2012. Publ. 10.06.2013, Bul. 2012; 11: 111-7 (in Ukrainian).

28.Solohubova S, Lakhno O, Shyyan V, Shyyan O. The Assessment of Physical Fitness and Morphofunctional State of Female First-Year Students in NonLinguistic Higher Education Institutions. Teoriâ Ta Metodika Fìzičnogo Vihovannâ, 2020;20(3), 157-164. https://doi.org/10.17309/tmfv.2020.3.05 
29.Koryahin V, Blavt O. Pedagogical Principles of Control in Physical Education of Students of Special Medical Groups. Teorîa Ta Metodika Fìzičnogo Vihovannâ, 2017;17(3), 107-116. https://doi.org/10.17309/tmfv.2017.3.1195

30.Heimbürge S, Kanitz E, Otten W. The use of hair cortisol for the assessment of stress in animals. Gen Comp Endocrinol. 2019; 270: 10-7. https://doi.org/10.1016/j.ygcen.2018.09.016

31.Fukasawa M, Kawakami N, Umeda M, Akiyama T, Horikoshi $\mathrm{N}$, Yasumura S, et al. Longitudinal associations of radiation risk perceptions and mental health among non-evacuee residents of Fukushima prefecture seven years after the nuclear power plant disaster. SSM - Population Health. 2020; 10: 100523. https://doi.org/10.1016/j.ssmph.2019.100523

32.Kashiwazaki Y, Takebayashi Y, Murakami M. Relationships between radiation risk perception and health anxiety, and contribution of mindfulness to alleviating psychological distress after the Fukushima accident: Cross-sectional study using a path model. PloS ONE. 2020; 15(7): e0235517. https://doi.org/10.1371/journal.pone.0235517

33. Moreels M, Baselet B, Van Hoey O, Vanhavere F, Baatout S. Stress and radiation responsiveness. In: Stress Challenges and Immunity in Space. Springer, Cham; 2020. P. 373-404. https://doi.org/10.1007/978-3-030-16996-1_20

34.Stalder T, Kirschbaum C, Alexander N, Bornstein SR, Gao W, Miller R, et al. Cortisol in hair and the metabolic syndrome. J Clin Endocrinol Metab. 2013; 98(6): 2573-80. https://doi.org/10.1210/jc.2013-1056

35.Mazgelytė E, Karčiauskaitė D, Linkevičiūtè A, Mažeikienè A, Burokienė $\mathrm{N}$, Matuzevičienė $\mathrm{R}$, et al. Association of hair cortisol concentration with prevalence of major cardiovascular risk factors and allostatic load. Medical Science Monitor. 2019; 25: 3573. https://doi.org/10.12659/MSM.913532

36. Ottosson M, Vikman-Adolfsson K, Enerbäck S, Olivecrona G, Björntorp P. The effects of cortisol on the regulation of lipoprotein lipase activity in human adipose tissue. The J Clin Endocrinol Metab. 1994; 79(3): 820-5. https://doi.org/10.1210/jcem.79.3.8077367

37.Petrichenko IE, Daret D, Kolpakova GV, Shakhov YA, Larrue J. Glucocorticoids stimulate cholesteryl ester formation in human smooth muscle cells. Arterioscler Thromb Vasc Biol. 1997; 17(6): 1143-51. https://doi.org/10.1161/01.ATV.17.6.1143

38. Feingold KR, Brinton EA, Grunfeld C. The effect of endocrine disorders on lipids and lipoproteins. In: Endotext [Internet]. MDText. com, Inc; 2020. Available from: https:// www.ncbi.nlm.nih.gov/sites/books/NBK409608/

39.Brumby S, Chandrasekara A, Kremer P, Torres S, McCoombe S, Lewandowski P. The effect of physical activity on psychological distress, cortisol and obesity: results of the farming fit intervention program. BMC Public Health. 2013; 13(1): 1018. https://doi.org/10.1186/1471-2458-13-1018

40.MacAuley D, McCrum EE, Stott G, Evans AE, Duly E, Trinick TR, et al. Physical activity, lipids, apolipoproteins, and Lp (a) in the Northern Ireland Health and Activity Survey. Med Sci Sports Exerc. 1996; 28(6): 720-36. https://doi.org/10.1097/00005768-199606000-00011

41.Tolfrey K, Campbell IG, Batterham AM. Exercise training induced alterations in prepubertal children's lipid-lipoprotein profile. Med Sci Sports Exerc. 1998; 30(12): 1684-92.

42.Kostka T, Lacour JR, Berthouze SE, Bonnefoy M. Relationship of physical activity and fitness to lipid and lipoprotein (a) in elderly subjects. Med Sci Sports Exerc. 1999; 31(8): 1183-9. https://doi.org/10.1097/00005768-199908000-00016

43.Jia X, Lorenz P, Ballantyne CM. Poststatin Lipid Therapeutics: AReview.MethodistDebakey CardiovascJ.2019;15(1):32-8. https://doi.org/10.14797/mdcj-15-1-32

44.Khan SU, Rahman H, Okunrintemi V, RiazH, Khan MS, Sattur $\mathrm{S}$, et al. Association of Lowering Low-Density Lipoprotein Cholesterol With Contemporary Lipid-Lowering Therapies and Risk of Diabetes Mellitus: A Systematic Review and Meta-Analysis. J Amer Heart Assoc. 2019; 8(7): e011581. https://doi.org/10.1161/JAHA.118.011581

45.Madsen CM, Varbo A, Nordestgaard BG. Extreme high highdensity lipoprotein cholesterol is paradoxically associated with high mortality in men and women: two prospective cohort studies. Eur Heart J. 2017; 38(32): 2478-86. https://doi.org/10.1093/eurheartj/ehx163

46.Riaz H, Khan SU, Rahman H, Shah NP, Kaluski E, Lincoff $\mathrm{AM}$, et al. Effects of high-density lipoprotein targeting treatments on cardiovascular outcomes: A systematic review and meta-analysis. Eur J Prev Cardiol. 2019; 26(5): 533-43. https://doi.org/10.1177/2047487318816495

47.Alexopoulos AS, Qamar A, Hutchins K, Crowley MJ, Batch BC, Guyton JR. Triglycerides: emerging targets in diabetes care? Review of moderate hypertriglyceridemia in diabetes. Curr Diabetes Rep. 2019; 19(4): 13. https://doi.org/10.1007/s11892-019-1136-3

48.Laufs U, Parhofer KG, Ginsberg HN, Hegele RA. Clinical review on triglycerides. Eur Heart J. 2020; 41(1): 99-109. https://doi.org/10.1093/eurheartj/ehz785

49. Godsland IF, Leyva F, Walton C, Worthington M, Stevenson JC. Associations of smoking, alcohol and physical activity with risk factors for coronary heart disease and diabetes risk in the first follow-up cohort of the Heart Disease and Diabetes Risk Indicators in a Screened Cohort study (HDDRISC-1). $J$ Intern Med. 1998; 243(7): 33-41. https://doi.org/10.1111/j.1365-2796.1998.00312.x

50.Albarrati AM, Alghamdi MSM, Nazer RI, Alkorashy MM, Alshowier N, Gale N. Effectiveness of low to moderate physical exercise training on the level of low-density lipoproteins: Asystematic review. BioMed Res Int. 2018; 2018. https://doi.org/10.1155/2018/5982980

51.Lira FS, Yamashita AS, Uchida MC, Zanchi NE, Gualano B, Martins E, et al. Low and moderate, rather than high intensity strength exercise induces benefit regarding plasma lipid profile. Diabetol Metab Syndr. 2010; 2(1): 31. https://doi.org/10.1186/1758-5996-2-31

52.O'Donovan G, Owen A, Bird SR, Kearney EM, Nevill $\mathrm{AM}$, Jones DW, et al. Changes in cardiorespiratory fitness and coronary heart disease risk factors following 24 wk of moderate-or high-intensity exercise of equal energy cost. $J$ Appl Physiol. 2005; 98(5): 1619-25. https://doi.org/10.1152/japplphysiol.01310.2004

53.Ha CH, So WY. Effects of combined exercise training on body composition and metabolic syndrome factors. Iran $J$ Public Health. 2012; 41(8): 20-6.

54.Sacheck JM, Kuder JF, Economos CD. Physical fitness, adiposity, and metabolic risk factors in young college students. Med Sci Sports Exerc. 2010; 42(6): 1039-44. https://doi.org/10.1249/mss.0b013e3181c9216b

55.Costa RR, Lima CA, Tagliari M, Martins LK. Effects of resistance training on the lipid profile in obese women. $J$ Sport Med Phys Fit. 2011; 51(1): 169-77.

56.Diaba-Nuhoho P, Ofori EK, Asare-Anane H, Oppong SY, Boamah I, Blackhurst D. Impact of exercise intensity on oxidative stress and selected metabolic markers in young 
adults in Ghana. BMC Research Notes. 2018; 11(1): 634. https://doi.org/10.1186/s13104-018-3758-y

57.Awobajo FO, Olawale OA, Bassey S. Changes in blood glucose, lipid profile and antioxidant activities in trained and untrained adult male subjects during programmed exercise on the treadmill. Nig QJ Hosp Med. 2013; 23(2): 117-24.

58.Korshøj M, Ravn MH, Holtermann A, Hansen AM, Krustrup P. Aerobic exercise reduces biomarkers related to cardiovascular risk among cleaners: effects of a worksite intervention RCT. Int Arch Occup Environ Health. 2016; 89(2): 239-49. https://doi.org/10.1007/s00420-015-1067-5

59.Monda KL, Ballantyne CM, North KE. Longitudinal impact of physical activity on lipid profiles in middle-aged adults: the Atherosclerosis Risk in Communities Study. J Lipid Res. 2009; 50(8): 1685-91. https://doi.org/10.1194/jlr.P900029-JLR200

60.Bogdanovska NV, Simonik AV, Korkach YuP, Sagach VF. The intensity of oxidative metabolism and production of nitric oxide in female students during adaptation to physical load. Fiziol Zh. 2018; 64(5): 32-40. (in Ukrainian). https://doi.org/10.15407/fz64.05.032

61.Bogdanovskaya NV, Kotsuruba AV, Golubenko AV. Induction of oxidative and nitrosative stress in boys in adapting to physical stress during training and competitive periods]. Fiziol Zh. 2016; 62(2): 47-56. (in Ukrainian) https://doi.org/10.15407/fz62.02.047

62.Bogdanovs'ka NV, Kotsuruba AV, Symonik AV. Induction of Oxidative and Nitrosative Stress in Young Males in Adapting to Muscular Load during Training and Competitive Periods. Int J Physiol Pathophysiol. 2017; 8(2): 99-109. https://doi.org/10.1615/IntJPhysPathophys.v8.i2.10

63.de Gonzalo-Calvo D, Fernández-García B, de Luxán-Delgado B, Rodríguez-González S, García-Macia M, Suárez FM, et al. Chronic training increases blood oxidative damage but promotes health in elderly men. Age. 2013; 35(2): 407-17. https://doi.org/10.1007/s11357-011-9358-6

64.Alfred EF, Olu AB, Joy EI, Sunday J, Dennis A. The levels of C-reactive protein, malondialdehyde and absolute lymphocyte counts in Pre and post-acute exercise. J Sports Med Doping Stud. 2017; 7: 2161-0673. https://doi.org/10.4172/2161-0673.1000188

65.Santos-Silva A, Rebelo MI, Castro EMB, Belo L, Guerra A, Rego C, et al. Leukocyte activation, erythrocyte damage, lipid profile and oxidative stress imposed by high competition physical exercise in adolescents. Clin Chim Acta. 2001; 306(1-2): 119-26. https://doi.org/10.1016/S0009-8981(01)00406-5

66.Pal S, Chaki B, Chattopadhyay S, Bandyopadhyay A. Highintensity exercise induced oxidative stress and skeletal muscle damage in postpubertal boys and girls: A comparative study. J Strength Cond Res. 2018; 32(4): 1045-52. https://doi.org/10.1519/JSC.0000000000002167

67.Niess AM, Hartmann A, Grünert-Fuchs M, Poch B, Speit G. DNA damage after exhaustive treadmill running in trained and untrained men. Intl J Sports Med. 1996; 17(06): 397-403. https://doi.org/10.1055/s-2007-972868

68.Miyazaki H, Oh-ishi S, Ookawara T, Kizaki T, Toshinai $\mathrm{K}$, $\mathrm{Ha} \mathrm{S}$, et al. Strenuous endurance training in humans reduces oxidative stress following exhausting exercise. Eur J Appl Physiol. 2001; 84(1-2): 1-6. https://doi.org/10.1007/s004210000342

69.Custodio-Mendoza JA, Valente IM, Ramos RM, Lorenzo RA, Carro AM, Rodrigues JA. Analysis of free malondialdehyde in edible oils using gas-diffusion microextraction. J Food Compos Anal. 2019; 82: 103254. https://doi.org/10.1016/j.jfca.2019.103254

70.Fadaei R, Koushki M, Sharafkhaneh A, Moradi N, Ahmadi R, Rostampour M, et al. The impact of continuous positive airway pressure therapy on circulating levels of malondialdehyde: a systematic review and meta-analysis. Sleep Med. 2020. https://doi.org/10.1016/j.sleep.2020.02.014

71.Atashak S, Sharafi H. Plasma malondialdehyde response to aerobic exercise after T. polium supplementation. Eur J Exp Biol. 2013; 3(2): 499-502.

72.Puspaningtyas DE, Afriani Y, Mahfida SL, Kushartanti W, Farmawati A. Effect of exercise on lipid peroxidation in student soccer players. In. J Med Sci. 2018; 50(1): 91-100. https://doi.org/10.19106/JMedSci005001201811

73.Pangkahila EA, Adiputra N, Pangkahila W, Yasa IWPS. Balanced physical exercise increase physical fitness, optimize endorphin levels, and decrease malondialdehyde levels. Bali Med J. 2016; 5(3): 493-6. https://doi.org/10.15562/bmj.v5i3.337

74.Dede ND, Ipekci S, Kebapcilar L, Arslan M, Kurban $\mathrm{S}$, Yildiz $\mathrm{M}$, et al. Effect of aerobic exercise training on serum malondialdehyde level and quality of life in type 2 diabetes. Endocrine Abstracts. 2018; 56: GP100. https://doi.org/10.1530/endoabs.56.GP100

75.Biswal S, Rizwan H, Pal S, Sabnam S, Parida P, Pal A. Oxidative stress, antioxidant capacity, biomolecule damage, and inflammation symptoms of sickle cell disease in children. Hematology. 2019; 24(1): 1-9. https://doi.org/10.1080/10245332.2018.1498441

76.Myke-Mbata BK, Meludu SC, Dioka CE. Antioxidant Supplementation and Free Radicals Quelling; the Pros and Cons. J Adv Med Med Res. 2018; 25(6): 1-13. https://doi.org/10.9734/JAMMR/2018/39938

77.StepanovaN,KorolL,BurdeynaO.Oxidativestressinperitoneal dialysis patients: association with the dialysis adequacy and technique survival. Indian J Nephrol. 2019; 29(5): 309-16. https://doi.org/10.4103/ijn.IJN_242_18

78.Wang B, Wang XP. Does ceruloplasmin defend against neurodegenerative diseases? Curr Neuropharmacol. 2019; 17(6): 539-49. https://doi.org/10.2174/1570159X16666180508113025

79.Karpov VY, Zavalishina SY, Romanova AV, Voevodina TM. Physiological mechanisms of rehabilitation in vegetative vascular dystonia. Indian $J$ Public Health Res Dev. 2019; 10(10): 1261-5. https://doi.org/10.5958/0976-5506.2019.03005.5

80.Tinken TM, Thijssen DH, Hopkins N, Dawson EA, Cable NT, Green DJ. Shear stress mediates endothelial adaptations to exercise training in humans. Hypertension. 2010;55(2):312-8. https://doi.org/10.1161/HYPERTENSIONAHA.109.146282

81.Radak Z, Ihasz F, Koltai E, Goto S, Taylor AW, Boldogh I. The redox-associated adaptive response of brain to physical exercise. Free Radic Res. 2014; 48(1): 84-92. https://doi.org/10.3109/10715762.2013.826352

82.Radak Z, Suzuki K, Higuchi M, Balogh L, Boldogh I, Koltai E. Physical exercise, reactive oxygen species and neuroprotection. Free Radic Biol Med. 2016; 98: 187-96. https://doi.org/10.1016/j.freeradbiomed.2016.01.024

83.Radak Z, Taylor AW. Exercise and hormesis. In: Rattan SIS, Kyriazis M, editors, The Science of Hormesis in Health and Longevity. Academic Press; 2019. P. 63-73. https://doi.org/10.1016/B978-0-12-814253-0.00005-X

84.Radak Z, Chung HY, Goto S. Exercise and hormesis: oxidative stress-related adaptation for successful aging. Biogerontology. 2005; 6(1): 71-5. https://doi.org/10.1007/s10522-004-7386-7 
85.Asbrand J, Heinrichs N, Nitschke K, Wolf OT, Schmidtendorf S, Tuschen-Caffier B. Repeated stress leads to enhanced cortisol stress response in child social anxiety disorder but this effect can be prevented with CBT. Psychoneuroendocrinology, 2019; 109: 104352. https://doi.org/10.1016/j.psyneuen.2019.06.003

\section{Information about the authors:}

Vadym L. Sokolenko; (Corresponding Author); Candidate of Biology, associate prof.; http://orcid.org/0000-0002-3096-8245; sokolenko@ukr.net; Bohdan Khmelnytsky National University of Cherkasy, Shevchenko str., 81, Chercasy, 18031, Ukraine.

Svitlana V. Sokolenko; Candidate of Biology, associate prof.; http://orcid.org/0000-0002-7341-1762; sokolenko@ukr.net; Bohdan Khmelnytsky National University of Cherkasy, Shevchenko str., 81, Chercasy, 18031, Ukraine.

\section{Cite this article as:}

Sokolenko VL, Sokolenko SV. Parameters of lipid and oxidative-antioxidant status in persons aged 18-23 from radiationcontaminated areas under conditions of moderate physical activity. Physical Education of Students, 2020;24(5):293303.

https://doi.org/10.15561/20755279.2020.0506

This is an Open Access article distributed under the terms of the Creative Commons Attribution License, which permits unrestricted use, distribution, and reproduction in any medium, provided the original work is properly cited http://creativecommons.org/licenses/by/4.0/deed.en

Received: 15.09.2020

Accepted: 15.10.2020; Published: 30.10.2020 